\title{
Letter \\ Vasopressor stays vasopressor and inotrope stays inotrope!
} Günter Luckner ${ }^{1}$, Walter R Hasibeder ${ }^{2}$ and Martin W Dünser ${ }^{1}$

\begin{abstract}
${ }^{1}$ Department of Anesthesiology and Critical Care Medicine, Innsbruck Medical University, Anichstrasse, 6020 Innsbruck, Austria 2Department of Anesthesiology and Critical Care Medicine, Krankenhaus der Barmherzigen Schwestern, Ried im Innkreis, Austria
\end{abstract}

Corresponding author: Martin W Dünser, Martin.Duenser@i-med.ac.at

Published: 14 April 2008

This article is online at http://ccforum.com/content/12/2/415

(C) 2008 BioMed Central Ltd

See related research by Müller et al., http://ccforum.com/content/12/1/R20
Critical Care 2008, 12:415 (doi:10.1186/cc6850)
We should like to comment on the interesting work reported by Müller and colleagues [1]. We feel that the results of their experiment were predictable and that arginine vasopressin (AVP) was not indicated in that setting. Infusing a vasoconstrictor without relevant inotropic potential in an acute low flow state with maintained or increased vascular tone must further augment organ vascular resistance and thereby reduce cardiac output. In the critical care setting, a vasopressor can only be beneficial in patients with pathological vasodilatation, whereas patients with low systemic blood flow and maintained vascular tone require either fluids and/or an inotrope. In their report Müller and colleagues indiscriminately interchange vasodilatory and cardiogenic shock. However, these forms of shock must be strictly separated when considering the use of a strong vasopressor such as AVP. Some patients with cardiogenic shock will subsequently develop an additional vasodilatory component [2]. Although they require an inotrope at early stages, a vasopressor may be useful to restore a (sub)normal vascular tone at later stages.

We therefore believe that this experiment does not appropriately reflect the clinical situation and does not support the conclusion that AVP, as a rule, should not be applied in patients with myocardial infarction and cardiogenic shock. Indeed, preliminary clinical experience suggests that when overwhelming systemic inflammation translates into vasodilatation in some patients with cardiogenic shock, the addition of AVP (attaining plasma levels as observed after AVP withdrawal by Müller and coworkers [1]) can decrease high catecholamine dosages, thus attenuating adrenergic stress and myocardial oxygen demand [3].

\section{Authors' response \\ Ole-Jakob How, Stig Müller and Truls Myrmel}

It was not our intention to 'indiscriminately interchange vasodilatory and cardiogenic shock', and we do not think that the report in fact can be interpreted in that way. On the contrary, our experimental design was aimed at testing the 'clean' effect of vasopressin in the setting of postischaemic left ventricular dysfunction. The reason for conducting these experiments was prompted by a series of reports questioning the vasoconstrictive effect of vasopressin in the coronary, pulmonary and cerebral circulations [4], and the inclusion of the drug among the treatment options for cardiogenic shock $[5,6]$. Our limited clinical experience with the drug in this clinical setting mandates great caution.

An assessment of the effect of vasopressin as monotherapy in an experimental setting, in our opinion, makes an important contribution to our understanding of this agent's effect in a circulation supported by a postischaemic and failing heart. Our observations raise serious concerns, particularly because the drug appeared to override the metabolic regulation of the coronary circulation. We therefore agree with the comment by Parillo [7] in a recent editorial included in the New England Journal of Medicine on the effect of vasopressin in sepsis; '... the equivalence in the rate of adverse events seen in the two groups probably resulted, in part, from ensuring that patients with underlying heart disease were not entered in the trial. Without these exclusions, it is possible that vasopressin might have increased the mortality rate.'

\section{Competing interests}

The authors declare that they have no competing interests. 


\section{References}

1. Müller S, How OJ, Hermansen SE, Stenberg TA, Sager G, Myrmel $\mathrm{T}$ : Vasopressin impairs brain, heart and kidney perfusion: an experimental study in pigs after transient myocardial ischemia. Crit Care 2008, 12:R20.

2. Landry DW, Oliver JA: The pathogenesis of vasodilatory shock. N Engl J Med 2001, 345:588-595.

3. Mayr VD, Luckner G, Jochberger S, Wenzel V, Hasibeder WR, Dünser MW: Vasopressin as a rescue vasopressor agent. Treatment of selected cardiogenic shock states. Anaesthesist 2007, 56:1017-1020.

4. Holmes CL, Patel BM, Russell JA, and Walley KR: Physiology of vasopressin relevant to management of septic shock. Chest 2001, 120:989-1002.

5. Jolly S, Newton G, Horlick E, Seidelin PH, Ross HJ, Husain M, Dzavik V: Effect of vasopressin on hemodynamics in patients with refractory cardiogenic shock complicating acute myocardial infarction. Am J Cardiol 2005, 96:1617-1620.

6. Luckner G, Dünser MW, Jochberger S, Mayr VD, Wenzel V, Ulmer H, Schmid S, Knotzer H, Pajk W, Hasibeder W, Mayr AJ, Friesenecker B: Arginine vasopressin in $\mathbf{3 1 6}$ patients with advanced vasodilatory shock. Crit Care Med 2005, 33:2659-2666.

7. Parrillo JE: Septic shock: vasopressin, norepinephrine, and urgency. N Engl J Med 2008, 358:954-956. 